\title{
Polymorphisms of serotonin neurotransmission and their effects on antipsychotic drug action
}

\section{Document Version}

Final published version

Link to publication record in Manchester Research Explorer

\section{Citation for published version (APA):}

Tang, H., Reynolds, G. P., \& McGowan, O. (2014). Polymorphisms of serotonin neurotransmission and their effects on antipsychotic drug action. Pharmacogenomics.

\section{Published in:}

Pharmacogenomics

\section{Citing this paper}

Please note that where the full-text provided on Manchester Research Explorer is the Author Accepted Manuscript or Proof version this may differ from the final Published version. If citing, it is advised that you check and use the publisher's definitive version.

\section{General rights}

Copyright and moral rights for the publications made accessible in the Research Explorer are retained by the authors and/or other copyright owners and it is a condition of accessing publications that users recognise and abide by the legal requirements associated with these rights.

\section{Takedown policy}

If you believe that this document breaches copyright please refer to the University of Manchester's Takedown Procedures [http://man.ac.uk/04Y6Bo] or contact uml.scholarlycommunications@manchester.ac.uk providing relevant details, so we can investigate your claim.

\section{OPEN ACCESS}




\section{Polymorphisms of serotonin neurotransmission and their effects on antipsychotic drug action}

The receptor pharmacology of many antipsychotic drugs includes actions at various serotonin (5-hydroxytryptamine [5-HT]) receptors. The 5-HT neurotransmitter system is thought to be involved in many of the consequences of treatment with antipsychotic drugs, including both symptom response, primarily of negative and depressive symptoms, and adverse effects, notably extrapyramidal side effects and weight gain. There is substantial interindividual variability in these drug effects, to which genetic variability contributes. We review here the influence of functional polymorphisms in genes associated with $5-\mathrm{HT}$ function, including the various processes of neurotransmitter synthesis, receptors, transporters and metabolism, on the clinical response to, and adverse effects of, antipsychotic drugs. The relatively young field of epigenetics also contributes to the variability of 5-HT-related genes in influencing drug response. Several of these findings inform our understanding of the mechanisms of antipsychotic drug action, and also provide the opportunity for the development of genetic testing for personalized medicine.

Keywords: 5-hydroxytryptamine $\bullet$ 5-HT receptors $\bullet$ antipsychotic drugs $\bullet$ gene

- neurotransmitters $\bullet$ schizophrenia $\bullet$ side effects $\bullet$ symptom response

\section{Background}

The antipsychotic drugs are prescribed to over $1 \%$ of the population in the developed world, not only as a treatment for schizophrenia and, increasingly, for mania in bipolar illness but also for various behavioral problems associated with neurodevelopmental (e.g., autism) and neurodegenerative (e.g., dementia) disorders. Despite their widespread use they are limited in their efficacy and tolerability; in general they exhibit far greater differences between individuals than between drugs. The reasons for these differences remain for the most part obscure, although accumulating evidence over the past two decades indicates a strong contribution from genetic factors to the symptom response and side effects of antipsychotic drug treatment. While the central role of dopamine in the mechanisms of antipsychotic action has meant that this neurotransmitter system has been a focus in pharmacogenetic studies $[1,2]$, equivalent effort has been expended in investigating candidate genes relating to 5-hydroxytryptamine (5-HT; serotonin) neurotransmission $[3,4]$. In this article we shall provide an overview of these studies, focus on some key findings and discuss the potential of 5-HT pharmacogenomics in terms of how they have informed our understanding of the mechanisms of antipsychotic drug action, and how they might contribute to genetic testing for personalized medicine.

\section{5-HT system in antipsychotic drug action}

5-HT has a widespread distribution in the human brain, with most neuronal cell bodies found in the dorsal and median raphe and neighboring nuclei of the lower brain stem. There are projections to the hippocampus, amygdala, hypothalamus, thalamus, neocortex and regions of the basal ganglia, although most structures receive some serotoninergic innervation. The known functions
Hao Tang ${ }^{1,2}$, Olga O McGowan ${ }^{3}$ \& Gavin P Reynolds ${ }^{*}, 2$

'Department of Neurology, First People's Hospital of Yunnan Province, Kunming, 650021 China

${ }^{2}$ Biomedical Research Centre,

Sheffield Hallam University, Howard St, Sheffield S1 1WB, UK ${ }^{3} \mathrm{NHS}$ Lanarkshire, Wishaw General Hospital, Wishaw ML2 ODP, UK *Author for correspondence: Tel.: +44 7740651500 gavin.reynolds@hotmail.com 
of these regions indicate that 5-HT may be involved in depressive and other psychiatric disorders, as well as cognitive and motor disturbances. Given the complex symptom profile of schizophrenia and the various side effects of its treatment with the antipsychotic drugs, it in unsurprising that 5-HT is thought to have a role in many aspects of antipsychotic drug action.

There is little doubt that the major mechanism underlying drug action in the treatment of schizophrenia involves antagonist action at the dopamine $\mathrm{D} 2$ receptor, which is also true of the antimanic effects of the antipsychotic drugs [5]. However, since the identification of the 'atypicality' of drugs such as clozapine and risperidone, there has been a strong focus on the role of 5-HT receptor antagonism in modifying, generally for the better, the effects of D2 antagonism [6,7]. In particular, the majority of the second-generation antipsychotics have a high affinity for 5-HT2A receptors; this is considered to contribute to a diminution of certain side effects as well as possibly to their symptom response profile. These drugs are increasingly being used in the treatment of both major depressive disorder and bipolar disorder; again serotoninergic mechanisms are thought to contribute.

Notwithstanding the central role of dopamine in antipsychotic action, 5-HT2A receptor agonism can provide a model of some paranoid psychotic symptoms of schizophrenia [8]. Relief of these positive symptoms is the main influence of the antipsychotic drugs in the treatment of schizophrenia. However there is little evidence to otherwise suggest that this action is anything other than the result of dopamine $\mathrm{D} 2$ receptor antagonism; certainly the high occupancy of 5-HT2A receptors by atypical antipsychotics is unrelated to clinical global improvement [9]. It is postulated that the 5-HT system, with pharmacogenetic evidence discussed below, may be involved in the negative symptoms of the disease, although again there is little evidence to support 5-HT2A antagonism by antipsychotic drugs being valuable in relieving these negative symptoms [10]. Nevertheless the strong involvement of 5-HT neurotransmission in depression and its treatment implicates effects on this system in the antidepressant and antisuicidal actions of some newer antipsychotics [7]. Furthermore, the 5-HT receptor effects of some antipsychotic drugs may well have effects on cognitive deficits associated with schizophrenia [11].

Regarding side effects, 5-HT2A antagonism appears to diminish the incidence of drug-induced extrapyramidal symptoms (EPS) - the mechanism considered to underlie the atypicality of many of the secondgeneration drugs. However, it cannot provide complete protection, with a dose-dependent emergence of EPS apparent for many of these antipsychotics. Other 5-HT receptors may also contribute to lowered EPS, including 5-HT2C and 5-HT1A. However, as EPS has become less of a concern in recent years, the metabolic side effects have come to the fore. Many of the antipsychotic drugs cause substantial weight gain, reflecting increased food intake and suggesting disruption of the hormonal control mechanisms acting on the hypothalamus; an antagonist action at the 5-HT2C receptor is likely to be important in those drugs with the greatest effects on bodyweight and which include olanzapine and clozapine [12]. Other 5-HT receptor actions may contribute to the relative protection against weight gain shown for aripiprazole and ziprasidone. The hyperprolactinemia seen with certain newer and many of the older antipsychotic drugs reflects antagonism at dopamine $\mathrm{D} 2$ receptors that provide an inhibitory control of prolactin secretion. 5-HT receptors are also involved in this mechanism, with opposing stimulatory effects; it may well be that action at, for example, 5-HT2C receptors contributes to the relative freedom from hyperprolactinemia seen with several antipsychotic drugs including olanzapine and asenapine [5].

\section{Candidate genes}

The identification of functionally relevant candidate genes in one neurotransmitter system, which might be associated with the clinical response to, and adverse effects of, antipsychotic drugs, needs to start with an understanding of the genes directly involved in the synaptic action of that neurotransmitter.

In the synthesis of 5-HT, the availability of tryptophan is normally rate imiting. The first factor determining tryptophan's availability for 5-HT synthesis in the CNS is its active transport across the blood-brain barrier by the large neutral amino acid transport system. It is then converted to 5-hydroxytryptophan by $\mathrm{TPH}$, present in two forms in humans. TPH1 is the major enzyme for peripheral and pituitary tryptophan hydroxylation, while the more recently discovered TPH2 is most involved in CNS 5-HT synthesis [13]. However, TPH1 is expressed widely in the mammalian brain during development and thus may modulate neurotrophic effects of serotonin at this stage [14]. The resultant neuronal 5-hydroxytryptophan is rapidly decarboxylated by AAAD to $5-\mathrm{HT}$, which is then taken up into secretory vesicles by VMAT, to be available for synaptic release. Once released into the synapse to influence neural transmission by effects at specific receptors, 5-HT is removed via a specific transporter found on the presynaptic neuronal membrane. Excess monoamine transmitter can also undergo metabolic removal by MAO, of which the A form (MAO-A) is responsible for 5-HT oxidation to 5-hydroxyindole acetic acid. 
Each of these enzymes and transporters are strong candidate genes for pharmacogenetic effects associated with the functional roles of serotoninergic neurotransmission. Similarly the receptors for 5-HT are also potential candidates; these comprise a family of seven receptors, several having genetically distinct subtypes of which the 5-HT1A, 5-HT2A and 5-HT2C receptor subtypes have been most studied in psychiatric pharmacogenetics. However, several other serotonin receptor genes are attracting interest owing to their potential involvement in the effects of some of the newer antipsychotic drugs. Other than the ionotrophic 5-HT3 receptor, they are all G-protein-linked receptors, found primarily at postsynaptic sites differentially distributed in the human CNS. 5-HT1A, 5-HT1B and 5-HT1D receptors have presynaptic effects as autoreceptors, modulating release and, for 5-HT1A, providing inhibitory control over neuronal activity.

The genes involved in signal transduction following 5-HT receptor activation provide further candidates, although they are not necessarily specific for 5-HT neurotransmission. These include the genes coding for the G-protein second-messenger system, including GNB3, and the several regulators of G-protein signaling proteins.

\section{Pharmacogenetic findings}

\section{5-HT synthesis}

Tryptophan entry into the brain is affected by the neutral amino acid transporters LAT1 and LAT2, and can be influenced by competitive inhibition from other large neutral amino acids. However, there appear to be no reports of the corresponding genes carrying polymorphisms that influence 5-HT function, and certainly no pharmacogenetic studies of antipsychotic drug action.

The first specific gene in the CNS 5-HT synthetic pathway is TPH2. While studied primarily in the context of mood disorders and antidepressant response with some positive findings, there are also reports, not always consistently replicated, of association with schizophrenia. One study investigating association of six TPH2 SNPs with short-term response to antipsychotic treatment showed no significant influence [15]; a positive pharmacogenetic association of TPH2 polymorphisms with effects of antipsychotic drug treatment has not been found, other than a reported association of one 5' SNP with diabetes in a relatively large group of subjects receiving antipsychotic treatment [16].

TPH1 has been more widely studied as a potential risk gene in schizophrenia. There is also a report of an intronic SNP 779A/C (rs1799913) being associated with treatment response to antipsychotics [17]. A nega- tive finding in respect to antipsychotic-induced weight gain has also been reported [18].

\section{5-HT transport}

Probably the most investigated gene in psychiatric pharmacogenetics is that for the neuronal $5-\mathrm{HT}$ transporter (HTT; SLC6A4), the site of action of many antidepressant drugs. This has a functional ins/del promoter polymorphism (HTTLPR) in which the short allele (del) results in a reduced transporter activity of the HTT protein due to lower expression. A G/A SNP within this sequence (rs25531), only present in the ins allele, also has functional activity in which the $G$ allele is reported to have effects equivalent to the HTTLPR del allele. A further intronic variable number tandem repeat, STin2, also influences gene expression (Table 1).

SLC6A4 polymorphisms have inevitably been widely investigated in affective disorders and antidepressant response, although little work has addressed the association with antipsychotic action. However, several reports have found an association of the short del allele of HTTLPR with poor response to clozapine or risperidone [36-38], the latter group studying a drug-naive cohort. Interestingly, when the effects on symptom subtypes have been investigated, it is an association with negative but not positive symptom response that is found [39].

There appear to be few other significant results of the association of this gene with the effects of antipsychotics. A significant association of the HTTLPR with BMI is reported in antipsychotic-treated subjects [16], although several other studies find no association with weight gain. Similarly, the evidence is against there being significant associations of this polymorphism with EPS or tardive dyskinesia (TD) $[16,38]$. There is, however, substantial scope to investigate the other functional SLC6A4 polymorphisms, and their combination/interaction, in these various side effects that may well involve serotoninergic neurotransmission.

The major gene responsible for VMAT in the human brain, SLC18A2, has received very little pharmacogenetic attention. One SNP in this gene emerged from a study of 2632 SNPs in 128 candidate genes as the strongest association with TD in the CATIE sample, although this did not meet the stringent criteria for statistical significance [40]. However, VMAT-2 is not particularly selective for any specific monoamine neurotransmitter. Thus while the association with TD was confirmed in a further study [41] where the authors also demonstrated an interaction with a DRD2 gene SNP, this finding was interpreted as involving dopamine, rather than 5-HT, neurotransmission in TD. 


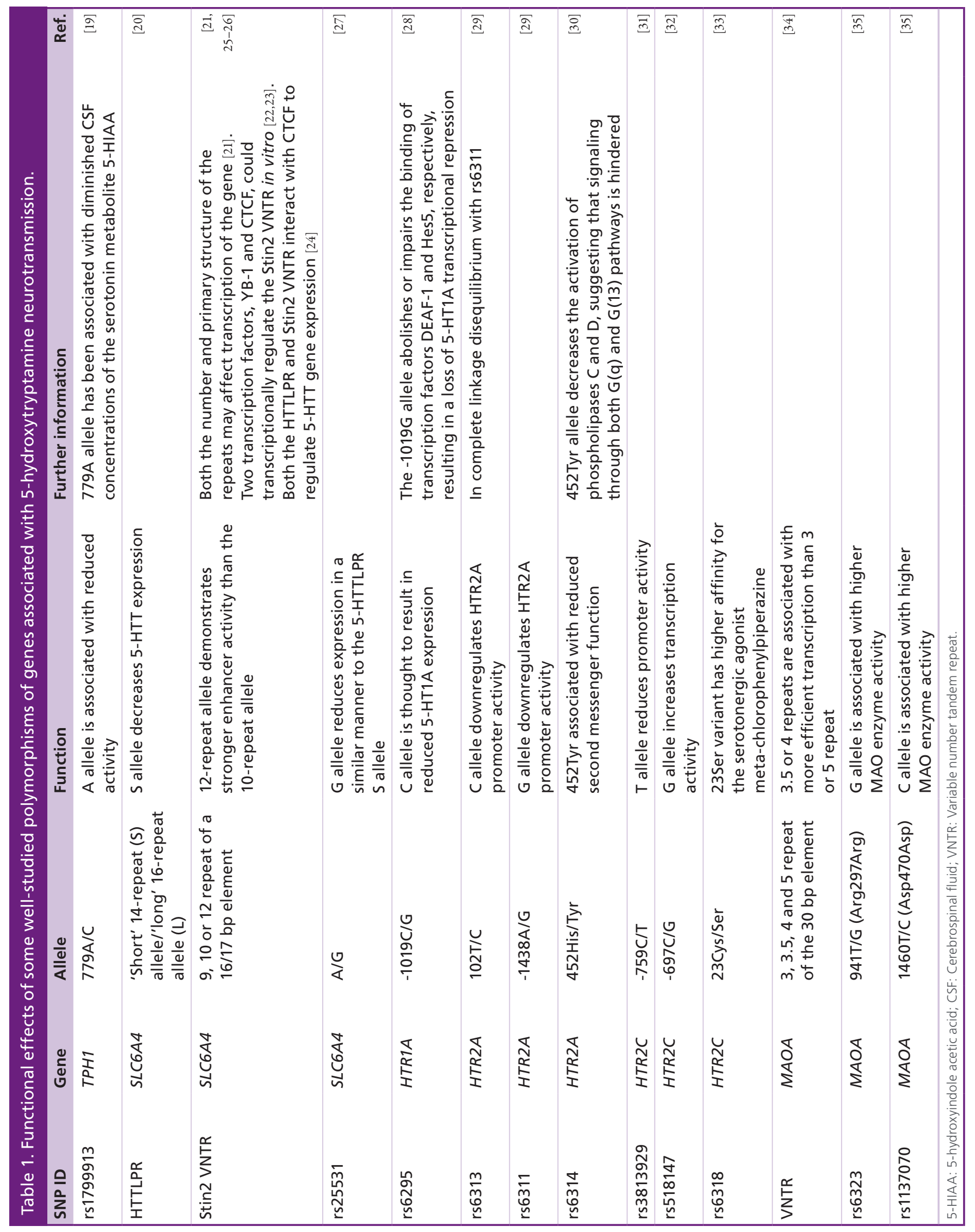




\section{5- $\mathrm{HT}$ receptors}

\section{5-HT1A receptor}

Only one of the HTR1A polymorphisms has been studied to any great extent: the promoter SNP $-1019 \mathrm{C} / \mathrm{G}$ (rs6295). This SNP was originally found to be associated with depression and suicidality and has a functional influence on receptor expression: the risk $\mathrm{G}$ allele disinhibits expression by disrupting the binding of inhibitory transcription factors [28] (Table 1). This theoretically results in overexpression of 5-HT1A autoreceptors with a consequent reduction in serotoninergic transmission (Table 1). rs6295 was found to influence symptom response to antipsychotic drug treatment through an effect on negative and depressive symptoms in a first-episode cohort [42], a robust finding that has been replicated by other groups $[43,44]$.

\section{5-HT2A receptor}

Of the 5-HT receptors it is 5-HT2A that has been most studied in schizophrenia and antipsychotic pharmacogenetics, reflecting the common high affinity of second-generation antipsychotic drugs for this site. The most studied polymorphisms are the 102T/C (rs6313), a synonymous coding region SNP, and $-1438 \mathrm{~A} / \mathrm{G}$ (rs6311), a promoter SNP that is in complete linkage with 102T/C and reportedly has functional effects on gene expression [29]. Specifically, the $-1438 \mathrm{G}$ allele may decrease promoter activity of HTR2A, leading to a downregulation of gene expression, although there are inconsistencies in the reported effects: Polesskaya et al. showed the $102 \mathrm{C}$ allele to be associated with upregulated expression [45]. A further functional nonsynonymous coding region SNP, 452His/Tyr (rs6314) [46], has also been identified (Table 1).

Reported associations with clinical response to antipsychotic treatment of these three SNPs have been reviewed [47]; perhaps surprisingly, findings regarding the $102 \mathrm{C} / \mathrm{T}$ site seems to be less consistent than those regarding $-1438 \mathrm{~A} / \mathrm{G}$, where the $\mathrm{A}$ allele appears to be associated with greater response. Samples from different populations may relate to this variability, as might differences in drug treatment. However, where symptom subgroups have been investigated, the association of these HTR2A SNPs appear more to be with negative symptoms rather than the positive symptoms [48-50]. These findings provide further evidence that 5-HT systems are important in negative symptoms and their response to antipsychotics [3]. Notably, a further indication that HTR2A variation can contribute to antipsychotic response comes from the CATIE cohort study by Need et al. [51]; they reported an intronic SNP in this gene to associate significantly $(\mathrm{p}<0.01)$ with improvement in the Positive and Negative Syn- drome Scale (PANSS) scores. However the associated site, one of 22 taken from an investigation of 2769 SNPs in 118 genes, did not differentiate effects on positive and negative symptoms.

From a theoretical view, it would seem that HTR2A polymorphisms would be better candidates for association with EPS. They have certainly been investigated in the chronic EPS of TD, in which a large metaanalytical study found a small association with $102 \mathrm{C} / \mathrm{T}$ but not with 452His/Tyr [52] while subsequent studies have provided inconsistent support [47]. Acute EPS, thought to be reduced by the 5-HT2A antagonism of newer antipsychotics, have been little studied, although one small study has shown association of undifferentiated EPS with HTR2A SNPs [53]. These SNPs have also been investigated in the context of antipsychoticinduced weight gain, with somewhat variable findings, although one study showed an effect on olanzapineinduced increases in weight of $102 \mathrm{C} / \mathrm{T}$ combined with several other SNPs in candidate genes [54].

\section{5-HT2C receptor}

The 5-HT2C receptor has also been implicated in EPS, particularly dyskinesias, and has shown in early studies some association of potentially functional SNPs with TD and also with aspects of symptom response [55]. However, the great majority of pharmacogenetic studies of this gene have been associated with the metabolic side effects of antipsychotic drugs. Following an initial study finding an association of a putatively functional HTR2C promoter SNP, -759C/T (rs3813929), with weight gain in firstepisode, initial drug naive, schizophrenia patients [56], there have been many pharmacogenetic studies addressing this problematic side effect. Despite some inconsistencies, most studies confirm a substantial effect of genetic variability in the HTR2C promoter and/or the coding region SNP 23Ser/Cys (rs6318), on weight gain, an association that appears to generalize across the effects of different drugs. This pharmacogenetic factor appears to be more strongly associated with initial gain in weight, while other genetic factors may be more associated with chronic effects on bodyweight [57]. Thus, despite a positive report [58], association of 5-HT2C receptor SNPs with the emergence of metabolic syndrome in patients receiving antipsychotic drugs has not been a consistent finding [59]. These observations have served to emphasize the role played by 5-HT2C receptor antagonism in the pharmacological mechanisms that result in antipsychotic-induced weight gain [12]. They also indicate how genetic testing for this and several polymorphisms in other genes might provide a valuable predictor of drug-induced weight gain [60]. 


\section{Other 5-HT receptors}

Pharmacogenetic associations with the clinical consequences of antipsychotic drug treatment have not been studied as extensively in the remaining 5-HT receptor genes. An intronic 5-HT4 receptor SNP was found to be associated with treatment response, and notably effects on cognitive symptoms, in the large candidate gene study of the CATIE sample, although this finding has not been replicated elsewhere.

A synonymous coding region SNP in the 5-HT6 receptor (267C/T; rs1805054) has been investigated in relation to a variety of psychiatric or cognitive measures; it was reported to be associated with response in positive and general psychopathology, but not negative, symptoms in patients receiving risperidone [60]. However, others have failed to replicate this finding [61].

Of the various genome-wide association study reports addressing antipsychotic pharmacogenetics, only one generated a positive finding for a 5-HT receptor gene. This emerged from the study of response in Phase III trials of the recently introduced antipsychotic iloperidone and identified a tagging SNP close to the 5-HT7 gene; no further findings provide support for this as a reliable candidate for antipsychotic response.

There still remains great potential in the further pharmacogenetic investigation of 5-HT receptor genes. The 5-HT1B receptor provides a valuable candidate gene, given its effects on the synaptic activity of serotonin and other neurotransmitters; in support there are reports of functional effects of several 5-HT1B receptor gene polymorphisms. Drug-induced weight gain and other metabolic effects also provide potential studies of interest with this and other 5-HT receptor genes. Similarly, there is a strong theoretical basis for further studies on the pharmacogenetics of 5-HT4 receptor polymorphisms, and particularly their role in the effects of drugs on cognitive symptoms, which remain inadequately treated in many people with schizophrenia.

\section{Regulation of G-protein signaling}

Pharmacogenetic studies of some genes associated with G-protein signaling have shown their involvement in both side effects and symptom response of antipsychotic drugs. While their involvement is inevitably not restricted to 5-HT neurotransmission, a few relevant reports are worth mentioning here. A meta-analysis reported a coding region polymorphism, C825T of GNB3, to be marginally associated with antipsychotic-induced weight gain [62]. This SNP also showed a 'trend-like' association with response to treatment with typical antipsychotics [17]. A SNP in the 3' region of $R G S 2$ with a functional effect on gene expression has been reported to be associated with
EPS caused by antipsychotic medications $[63,64]$. There is also some evidence indicating that variability in the $R G S 4$ gene, itself a reported risk factor for schizophrenia, is associated with symptom response, particularly in social function [65].

\section{5-HT metabolism}

The only enzyme directly involved in the metabolic removal of 5-HT is MAO-A. Widely studied in psychiatric disorders and in smoking behavior, this candidate has received little attention as a risk gene in symptom response or side effects of antipsychotic drugs. No consistent replicated findings have emerged, despite an early small study suggesting an additive influence of COMT and MAOA SNPs in treatment response of conventional antipsychotic drugs [66]. However, it might be argued that as MAO enzymes are generally unsaturated and in excess in the body, subtle differences in activity and concentration due to genetic variability may not have major effects on neurotransmitter function.

\section{Epigenetic studies}

A recent and highly topical approach to understanding genomic variation is in the field of epigenetics. One key epigenetic process is that of DNA methylation, which is an important inhibitory mechanism in the molecular processes controlling gene expression. DNA methylation involves the enzymatic methylation of cytosine at $\mathrm{CpG}$ sites; otherwise relatively rare in the human genome, these sites can occur in islands of high frequency, particularly in promoter regions involved in transcriptional regulation. DNA methylation of candidate genes has received interest in relation to depression and antidepressant response, but is now beginning to attract attention as a possible mechanism linking developmental problems such as early life trauma to other severe mental illness. Epigenetic factors might also contribute to pharmacogenomic influences on antipsychotic action. For example, DNA methylation can affect response to antipsychotics, and conversely can be modified by antipsychotic administration [67]. Diminished methylation of the HTR2A promoter sequence has been observed in schizophrenia [68]; although unstudied, this might further contribute to the variance in antipsychotic response associated with SNPs in this gene. One study has identified DNA methylation at a transcription factor binding site on the 5-HT1A receptor gene correlating with negative symptom response to antipsychotic treatment in first episode schizophrenia [69], a finding that complements the pharmacogenetic results at the adjacent rs6295 SNP [42]. This pharmacoepigenetic association with antipsychotic treatment is an early finding in a research 
field that is likely to see a rapid expansion in the very near future.

\section{Conclusion \& future perspective}

After two decades of research into the genetic factors underlying individual differences in symptom response and side effects of antipsychotic drugs, there still remains much to understand. It is apparent that genes related to 5-HT neurotransmission play an important role in this variability; notably in clinical response, particularly of negative symptoms, and in drug-induced weight gain among other side effects. This provides some insight into the underlying pharmacological mechanisms. There remain many inconsistencies in the scientific literature, and the inability of genomewide association studies to confirm many of the (often underpowered) single candidate gene associations is a concern. The generally much larger sample size of the former hypothesis-free approach has its strengths but also weaknesses: the generation of data from perhaps 1 million tagging SNPs, chosen for their distribution in the genome, has limitations in correction for multiple

\section{Executive summary}

\section{5-hydroxytryptamine system in antipsychotic drug action}

- The receptor pharmacology of many antipsychotic drugs includes actions at various serotonin (5-hydroxytryptamine [5-HT]) receptors. The 5-HT neurotransmitter system is thought to be involved in many of the consequences of treatment with antipsychotic drugs.

- The antipsychotic drug effects in which 5-HT systems are implicated include both symptom response, primarily of negative and depressive symptoms, and adverse effects, notably extrapyramidal side effects and weight gain.

\section{Pharmacogenetic findings}

- The 5-HT transporter gene (SLC6A4) polymorphism HTTLPR, much studied in the context of depression and antidepressant response, is also reportedly associated with antipsychotic response, particularly of negative symptoms.

- The 5-HT1A receptor gene (HTR1A) has a functional promoter SNP also associated with negative symptom response to antipsychotic drug treatment.

- HTR2A has been much studied, given that most second-generation antipsychotic drugs are antagonists at the 5-HT2A receptor. Most studied are a functionally active promoter SNP and a closely linked synonymous coding region SNP. Some association of these SNPs with symptom response has been reported, although association with acute extrapyramidal side effects has been little studied and tardive dyskinesia shows only a weak association.

- HTR2C has functional SNPs that have been studied in the promoter sequence as well as one in the coding region. Association with tardive dyskinesia has been reported, but the majority of studies have focused on metabolic effects. Promoter SNPs in HTR2C are associated with drug-induced weight gain, reflecting the role 5 -HT2C receptor antagonism plays in the pharmacology of this side effect.

- Few other 5-HT receptors have been much studied in the context of antipsychotic drug action. 5-HT4, 6 and 7 receptors are implicated in the clinical pharmacology of some antipsychotic drugs and their genes provide candidates for further pharmacogenetic studies.

\section{Epigenetic studies}

- Epigenetics provides a further approach to the pharmacogenomic investigation of individual variability in the effects of antipsychotic drugs. One epigenetic factor, DNA methylation, can both affect response to and be influenced by antipsychotic drugs.

- One study has found methylation adjacent to an HTR1A SNP to influence negative symptom response to antipsychotics, providing the first indication of the potential of functional epigenetic studies of the 5-HT system in antipsychotic drug effects.

\section{Conclusion \& future perspective}

- Pharmacogenomics of 5-HT systems contribute substantially to understanding individual variability of antipsychotic drug effects, particularly those of negative symptom response and weight gain.

- There remain many inconsistencies between studies, often due to sample differences, not all of which are acknowledged.

- For future progress, recognition that different functional polymorphisms in the 5-HT system may converge to have equivalent, interacting or additive effects is important, as is the integration of modern imaging techniques with pharmacogenomics to enlighten functionality in the living brain.

- Pharmacogenetic studies certainly contribute to a better understanding of the pharmacological mechanisms of antipsychotic drugs.

- These and future findings are likely to contribute to personalized medicine through the development of predictive testing for both efficacy of treatment with, and liability to the side effects of, antipsychotic drugs. 
testing and in the lack of a focus on functional polymorphisms. While the inevitable differences between cohorts in terms of drug treatments and ethnicity are recognized variables, one common problem that is rarely acknowledged is treatment nonadherence, suggesting blood monitoring could be a very valuable addition to pharmacogenetic studies.

Consideration of functional effects is, of course, important in understanding genetic association with drug actions. Several different genes may have an association with a particular clinical effect through a common pathway. We see this with the response of negative symptoms to antipsychotic treatment, for which there is evidence identified above for associations with functional SLC6A4, HTR1A and HTR2A polymorphisms, all of which are presumed to influence 5-HT synaptic activity [3]. Such findings indicate how the analysis of interactions between related genes, rather than separate single gene studies, may strengthen pharmacogenetic associations. Furthermore, there may well be interactions at a functional level as has been suggested from some imaging studies; the SLC6A4 polymorphism is associated with the activity of the 5-HT1A receptor as well as of its own gene product [70]. Thus one can envisage how SNPs in several genes related to serotoninergic neurotransmission may have a convergent influence on neuronal function and drug response. Future studies should consider such interactive and additive effects of genetic

\section{References}

Papers of special note have been highlighted as: • of interest

1 Scharfetter J. Pharmacogenetics of dopamine receptors and response to antipsychotic drugs in schizophrenia - an update. Pharmacogenomics 5(6), 691-698 (2004).

2 Shiroma PR, Geda YE, Mrazek DA. Pharmacogenomic implications of variants of monoaminergic-related genes in geriatric psychiatry. Pharmacogenomics 11(9), 1305-1330 (2010).

3 Reynolds GP. The pharmacogenetics of antipsychotic treatment. Handb. Exp. Pharmacol. 212, 213-239 (2012).

4 Brandl EJ, Kennedy JL, Müller DJ. Pharmacogenetics of antipsychotics. Can. J. Psychiatry 59(2), 76-88 (2014).

5 Reynolds GP. Receptor mechanisms of antipsychotic drug action in bipolar disorder - focus on asenapine. Ther. Adv. Psychopharmacol. 1(6), 197-204 (2011).

6 Ichikawa J, Ishii $\mathrm{H}$, Bonaccorso S, Fowler WL, O'Laughlin IA, Meltzer HY. 5-HT(2A) and D(2) receptor blockade increases cortical DA release via 5-HT(1A) receptor activation: a possible mechanism of atypical antipsychoticinduced cortical dopamine release. J. Neurochem. 76(5), 1521-1531 (2001).

7 Meltzer HY, Li Z, Kaneda Y, Ichikawa J. Serotonin receptors: their key role in drugs to treat schizophrenia. Prog. variability in multiple genes within this serotoninergic pathway. Increasing emphasis on the integration of other techniques with pharmacogenetics, not only gene-expression studies but also functional imaging in vivo, will lead to a better understanding of the physiological consequences of genetic polymorphisms.

These findings of 5-HT-related polymorphisms associated with the various consequences of antipsychotic drug treatment inform us in two ways. One is that they provide some light on the mechanisms underlying drug response and side effects, as mentioned above. They also illustrate how, eventually, we may be able to develop genetic testing that can contribute to the assessment of individual predisposition to side effects or symptom response - an initial step towards effective personalized medicine.

\section{Financial \& competing interests disclosure}

$G$ Reynolds has received honoraria for lectures, fees for advisory board membership or travel support from the following pharmaceutical companies developing or marketing antipsychotic drugs: Janssen, Lundbeck, Otsuka, Bristol-Myers Squibb, Roche and Sunovion. The authors have no other relevant affiliations or financial involvement with any organization or entity with a financial interest in or financial conflict with the subject matter or materials discussed in the manuscript apart from those disclosed.

No writing assistance was utilized in the production of this manuscript.

Neuropsychopharmacol. Biol. Psychiatry 27(7), 1159-1172 (2003).

8 Gouzoulis-Mayfrank E, Heekeren K, Neukirch A et al. Psychological effects of $(S)$-ketamine and $N, N$ dimethyltryptamine (DMT): a double-blind, cross-over study in healthy volunteers. Pharmacopsychiatry 38(6), 301-311 (2005).

9 Travis MJ, Busatto GF, Pilowsky LS et al. 5-HT2A receptor blockade in patients with schizophrenia treated with risperidone or clozapine. A SPET study using the novel 5-HT2A ligand 123I-5-I-R-91150. Br. J. Psychiatry 173, 236-241 (1998).

10 Reimold M, Solbach C, Noda S et al. Occupancy of dopamine $\mathrm{D}(1), \mathrm{D}(2)$ and serotonin (2A) receptors in schizophrenic patients treated with flupentixol in comparison with risperidone and haloperidol. Psychopharmacology (Berl.) 190(2), 241-249 (2007)

11 Schreiber R, Newman-Tancredi A. Improving cognition in schizophrenia with antipsychotics that elicit neurogenesis through 5-HT1A receptor activation. Neurobiol. Learn. Mem. 110, 72-80 (2014).

12 Reynolds GP, Kirk SL. Metabolic side effects of antipsychotic drug treatment-pharmacological mechanisms. Pharmacol. Ther. 125(1), 169-179 (2010). 
13 Zill P, Buttner A, Eisenmenger W, Muller J, Moller HJ, Bondy B. Predominant expression of tryptophan hydroxylase 1 mRNA in the pituitary: a postmortem study in human brain. Neuroscience 159(4), 1274-1282 (2009).

14 Nakamura K, Sugawara Y, Sawabe K et al. Late developmental stage-specific role of tryptophan hydroxylase 1 in brain serotonin levels. J. Neurosci. 2(2), 530-534 (2006).

15 Schuhmacher A, Becker T, Rujescu D et al. Investigation of tryptophan hydroxylase 2 (TPH2) in schizophrenia and in the response to antipsychotics. J. Psychiatr. Res. 46(8), 1073-1080 (2012).

16 Al-Janabi I, Arranz MJ, Blakemore AI et al. Association study of serotonergic gene variants with antipsychotic-induced adverse reactions. Psychiatr. Genet. 19(6), 305-311 (2009).

17 Anttila S, Kampman O, Illi A, Rontu R, Lehtimäki T, Leinonen E. Association between 5-HT2A, TPH1 and GNB3 genotypes and response to typical neuroleptics: a serotonergic approach. BMC Psychiatry 7, 22 (2007).

18 Nowrouzi B, Souza RP, Zai C et al. Finite mixture regression model analysis on antipsychotics induced weight gain: investigation of the role of the serotonergic genes. Eur. Neuropsychopharmacol. 23(3), 224-228 (2013).

19 Jönsson EG, Goldman D, Spurlock G et al. Tryptophan hydroxylase and catechol-O-methyltransferase gene polymorphisms: relationships to monoamine metabolite concentrations in CSF of healthy volunteers. Eur. Arch. Psychiatry Clin. Neurosci. 247(6), 297-302 (1997).

20 Heils A, Teufel A, Petri S et al. Allelic variation of human serotonin transporter gene expression. J. Neurochem. 66(6), 2621-2624 (1996).

21 Lovejoy EA, Scott AC, Fiskerstrand CE, Bubb VJ, Quinn JP. The serotonin transporter intronic VNTR enhancer correlated with a predisposition to affective disorders has distinct regulatory elements within the domain based on the primary DNA sequence of the repeat unit. Eur. J. Neurosci. 17(2), 417-420 (2003).

22 Klenova E, Scott AC, Roberts J et al. YB-1 and CTCF differentially regulate the 5-HTT polymorphic intron 2 enhancer which predisposes to a variety of neurological disorders. J. Neurosci. 24(26), 5966-5973 (2004).

23 Haddley K, Vasiliou AS, Ali FR, Paredes UM, Bubb VJ, Quinn JP. Molecular genetics of monoamine transporters: relevance to brain disorders. Neurochem. Res. 33(4), 652-667 (2008).

24 Ali FR, Vasiliou SA, Haddley K et al. Combinatorial interaction between two human serotonin transporter gene variable number tandem repeats and their regulation by CTCF. J. Neurochem. 112(1), 296-306 (2010).

25 Fiskerstrand CE, Lovejoy EA, Quinn JP. An intronic polymorphic domain often associated with susceptibility to affective disorders has allele dependent differential enhancer activity in embryonic stem cells. FEBS Lett. 458(2), 171-174 (1999).

26 MacKenzie A, Quinn JP. A serotonin transporter gene intron 2 polymorphic region, correlated with affective disorders, has allele-dependent differential enhancer-like properties in the mouse embryo. PNAS 96(26), 15251-15255 (1999).
27 Hu XZ, Lipsky RH, Zhu G et al. Serotonin transporter promoter gain-of-function genotypes are linked to obsessive-compulsive disorder. Am. J. Hum. Genet. 78(5), 815-826 (2006).

28 Lemonde S, Turecki G, Bakish D et al. Impaired repression at a 5-HTla receptor gene polymorphism associated with MDD and suicide. J. Neurosci. 23, 8788-8799 (2003).

- Not only showed an association of a common polymorphism with depression, but also demonstrated the underlying mechanism involving disruption of a transcription factor binding site.

29 Parsons MJ, D’Souza UM, Arranz MJ, Kerwin RW, Makoff AJ. The -1438A/G polymorphism in the 5-hydroxytryptamine type $2 \mathrm{~A}$ receptor gene affects promoter activity. Biol. Psychiatry 56(6), 406-410 (2004).

30 Hazelwood LA, Sanders-Bush E. His452Tyr polymorphism in the human 5-HT2A receptor destabilizes the signaling conformation. Mol. Pharmacol. 66(5), 1293-1300 (2004).

31 Yuan X, Yamada K, Ishiyama-Shigemoto S, Koyama W, Nonaka K. Identification of polymorphic loci in the promoter region of the serotonin 5-HT2C receptor gene and their association with obesity and Type II diabetes. Diabetologia 43(3), 373-376 (2000).

32 Hill MJ, Reynolds GP. 5-HT2C receptor gene polymorphisms associated with antipsychotic drug action alter promoter activity. Brain Res. 1149, 14-17 (2007).

33 Okada M, Northup JK, Ozaki N, Russell JT, Linnoila M, Goldman D. Modification of human 5-HT(2C) receptor function by Cys23Ser, an abundant, naturally occurring amino-acid substitution. Mol. Psychiat. 9, 55-64 (2004).

34 Sabol SZ, Hu S, Hamer D. A functional polymorphism in the monoamine oxidase A gene promoter. Hum. Genet. 103(3), 273-279 (1998).

35 Hotamisligil GS, Breakefield XO. Human monoamine oxidase A gene determines levels of enzyme activity. $\mathrm{Am}$. J. Hum. Genet. 49(2), 383-392 (1991).

36 Arranz MJ, Munro J, Birkett J et al. Pharmacogenetic prediction of clozapine response. Lancet 355(9215), 1615-1616 (2000).

- Early study demonstrating the potential of pharmacogenetics in the prediction of response to treatment with clozapine. This led to a commercial predictive test, which is no longer available.

37 Wang L, Yu L, He G et al. Response of risperidone treatment may be associated with polymorphisms of HTT gene in Chinese schizophrenia patients. Neurosci. Lett. 414(1), 1-4 (2007).

38 Dolzan V, Serretti A, Mandelli L, Koprivsek J, Kastelic M, Plesnicar BK. Acute antipyschotic efficacy and side effects in schizophrenia: association with serotonin transporter promoter genotypes. Prog. Neuropsychopharmacol. Biol. Psychiatry 32(6), 1562-1566 (2008).

39 Vázquez-Bourgon J, Arranz MJ, Mata I et al. Serotonin transporter polymorphisms and early response to antipsychotic treatment in first episode of psychosis. Psychiatry Res. 175(3), 189-194 (2010). 
40 Tsai HT, Caroff SN, Miller del D et al. A candidate gene study of tardive dyskinesia in the CATIE schizophrenia trial. Am. J. Med. Genet. B. Neuropsychiatr. Genet. 153B(1), 336-340 (2010).

41 Zai CC, Tiwari AK, Mazzoco M et al. Association study of the vesicular monoamine transporter gene SLC18A2 with tardive dyskinesia. J. Psychiatr. Res. 47(11), 1760-1765 (2013).

42 Reynolds GP, Arranz B, Templeman LA, Fertuzinhos S, San L. Effect of 5 HT1A receptor gene polymorphism on negative and depressive symptom response to antipsychotic treatment of drug-naive psychotic patients. Am. J. Psychiatry 163, 1826-1829 (2006).

- This replicated study found a strong association of HTR1A genotype with negative but not positive symptom response, emphasizing the differential association of polymorphisms with response of symptom subtypes to antipsychotic drug treatment.

43 Wang L, Fang C, Zhang A et al. The -1019 C/G polymorphism of the 5-HT(1)A receptor gene is associated with negative symptom response to risperidone treatment in schizophrenia patients. J. Psychopharmacol. 22(8), 904-909 (2008).

44 Mossner R, Schuhmacher A, Kühn KU et al. Functional serotonin $1 \mathrm{~A}$ receptor variant influences treatment response to atypical antipsychotics in schizophrenia. Pharmacogenet. Genomics 19(1), 91-94 (2009).

45 Polesskaya OO, Aston C, Sokolov BP. Allele C-specific methylation of the 5-HT2A receptor gene: evidence for correlation with its expression and expression of DNA methylase DNMT1. J. Neurosci. Res. 83(3), 362-273 (2006).

46 Reist C, Mazzanti C, Vu R, Fujimoto K, Goldman D. Inter-relationships of intermediate phenotypes for serotonin function, impulsivity, and a 5-HT2A candidate allele: His452Tyr. Mol. Psychiatry 9(9), 871-878 (2004).

47 Zhang JP, Malhotra AK. Pharmacogenetics and antipsychotics: therapeutic efficacy and side effects prediction. Expert Opin. Drug Metab. Toxicol. 7(1), 9-37 (2011).

48 Lane HY, Chang YC, Chiu CC, Chen ML, Hsieh MH, Chang WH. Association of risperidone treatment response with a polymorphism in the 5-HT(2A) receptor gene. Am. J. Psychiatry 159(9), 1593-1595 (2002).

49 Hamdani N, Bonnière M, Adès J, Hamon M, Boni C, Gorwood P. Negative symptoms of schizophrenia could explain discrepant data on the association between the 5-HT2A receptor gene and response to antipsychotics. Neurosci. Lett. 377(1), 69-74 (2005).

50 Ellingrod VL, Lund BC, Miller D et al. 5-HT2A receptor promoter polymorphism, -1438G/A and negative symptom response to olanzapine in schizophrenia. Psychopharmacol. Bull. 37(2), 109-112 (2003)

51 Need AC, Keefe RS, Ge D et al. Pharmacogenetics of antipsychotic response in the CATIE trial: a candidate gene analysis. Eur. J. Hum. Genet. 17(7), 946-957 (2009).

52 Lerer B, Segman RH. Pharmacogenetics of antipsychotic therapy: pivotal research issues and the prospects for clinical implementation. Dialogues Clin. Neurosci. 8(1), 85-94 (2006).

53 Gunes A, Scordo MG, Jaanson P, Dahl ML. Serotonin and dopamine receptor gene polymorphisms and the risk of extrapyramidal side effects in perphenazine-treated schizophrenic patients. Psychopharmacology (Berl.) 190(4), 479-484 (2007).

54 Ujike H, Nomura A, Morita Y et al. Multiple genetic factors in olanzapine-induced weight gain in schizophrenia patients: a cohort study. J. Clin. Psychiatry 69(9), 1416-1422 (2008).

55 Reynolds GP, Templeman LA, Zhang ZJ. The role of 5-HT2C receptor polymorphisms in the pharmacogenetics of antipsychotic drug treatment. Prog. Neuropsychopharmacol. Biol. Psychiatry 29(6), 1021-1028 (2005).

56 Reynolds GP, Zhang ZJ, Zhang XB. Association of antipsychotic drug-induced weight gain with a 5-HT2C receptor gene polymorphism. Lancet 359 (9323), 2086-2087 (2002).

- A much-replicated study demonstrating for the first time the association of a functional polymorphism with an important side effect of antipsychotic drug treatment.

57 Reynolds GP. Pharmacogenetic aspects of antipsychotic drug-induced weight gain - a critical review. Clin. Psychopharmacol. Neurosci. 10(2), 71-77 (2012).

58 Risselada AJ, Vehof J, Bruggeman R et al. Association between HTR2C gene polymorphisms and the metabolic syndrome in patients using antipsychotics: a replication study. Pharmacogenomics J. 12(1), 62-67 (2012).

59 Yevtushenko OO, Cooper SJ, O'Neill R, Doherty JK, Woodside JV, Reynolds GP. Influence of 5-HT2C receptor and leptin gene polymorphisms, smoking and drug treatment on metabolic disturbances in patients with schizophrenia. $\mathrm{Br}$. J. Psychiatry 192(6), 424-428 (2008).

60 Lane HY, Lin CC, Huang CH, Chang YC, Hsu SK, Chang WH. Risperidone response and 5-HT6 receptor gene variance: genetic association analysis with adjustment for nongenetic confounders. Schizophr. Res. 67(1), 63-70 (2004).

61 Ikeda M, Yamanouchi Y, Kinoshita Y et al. Variants of dopamine and serotonin candidate genes as predictors of response to risperidone treatment in first-episode schizophrenia. Pharmacogenomics 9(10), 1437-1443 (2008).

62 Souza RP, De Luca V, Muscettola G et al. Association of antipsychotic induced weight gain and body mass index with GNB3 gene: a meta-analysis. Prog. Neuropsychopharmacol. Biol. Psychiatry 32(8), 1848-1853 (2008).

63 Greenbaum L, Smith RC, Rigbi A et al. Further evidence for association of the RGS2 gene with antipsychotic-induced parkinsonism: protective role of a functional polymorphism in the 3'-untranslated region. Pharmacogenomics J. 9(2), 103-110 (2009).

64 Higa M, Ohnuma T, Maeshima $\mathrm{H}$ et al. Association analysis between functional polymorphism of the rs4606 SNP in the RGS2 gene and antipsychotic-induced Parkinsonism in Japanese patients with schizophrenia: results from the Juntendo University Schizophrenia Projects (JUSP). Neurosci. Lett. 469(1), 55-59 (2010). 
65 Lane HY, Liu YC, Huang CL et al. RGS4 polymorphisms predict clinical manifestations and responses to risperidone treatment in patients with schizophrenia. J. Clin. Psychopharmacol. 28(1), 64-68 (2008).

66 Illi A, Mattila KM, Kampman O et al. Catechol-Omethyltransferase and monoamine oxidase $\mathrm{A}$ genotypes and drug response to conventional neuroleptics in schizophrenia. J. Clin. Psychopharmacol. 23(5), 429-434 (2003).

67 Melas PA, Rogdaki M, Osby U, Schalling M, Lavebratt C, Ekstrom TJ. Epigenetic aberrations in leukocytes of patients with schizophrenia: association of global DNA methylation with antipsychotic drug treatment and disease onset. FASEB J. 26(6), 2712-2718 (2012).

68 Abdolmaleky HM, Yaqubi S, Papageorgis P et al. Epigenetic dysregulation of HTR2A in the brain of patients with schizophrenia and bipolar disorder. Schizophr. Res. 129(2-3), 183-190 (2011).

69 Tang H, Dalton CF, Srisawat U, Zhang ZJ, Reynolds GP. Methylation at a transcription factor-binding site on the 5-HT1A receptor gene correlates with negative symptom treatment response in first episode schizophrenia. Int. J. Neuropsychopharmacol. 17(4), 645-649 (2014).

- A first identification of an epigenetic variable contributing to treatment response to antipsychotic drugs, parallelling the effects of an adjacent polymorphism.

70 David SP, Murthy NV, Rabiner EA et al. A functional genetic variation of the serotonin (5-HT) transporter affects 5-HT1A receptor binding in humans. J. Neurosci. 25 (10), 2586-2590 (2005). 